\title{
Keratoconus Layer by Layer - Pathology and Matrix Metalloproteinases
}

\author{
Dasha Nelidova and Trevor Sherwin \\ Department of Ophthalmology, Faculty of Medical and Health Sciences, \\ University of Auckland, Auckland \\ New Zealand
}

\section{Introduction}

Keratoconus is an ectatic disease in which the cornea develops a conical shape due to thinning of the collagenous corneal stroma. Characteristic morphological features seen on slit lamp examination are well described. This overview describes the recent advances in our understanding of keratoconic pathology, focussing particularly on the matrix metalloproteinase hypothesis of keratoconus disease progression.

\section{The diversity and complexity of keratoconus}

Keratoconus is a corneal ectatic disease where the cornea assumes a conical shape due to thinning of the corneal stroma, inducing irregular astigmatism and myopia and leading to marked impairment of vision ${ }^{1}$. Keratoconus typically starts at puberty and progresses until the third or fourth decade of life; alternatively it may commence later and arrest at any age. This disease is associated with several conditions, particularly those which encourage eye rubbing.

The mechanism of disease progression has long been the subject of intense research; however, research is complicated by the large degree of variation in clinical features between patients. Forme fruste or sub-clinical forms of the disease, likely contribute to the differences in reported incidence are estimated to occur between 50 and 230 per 100,000 of the general population ${ }^{1}$. There are also significant geographical variations. New Zealand, for example, has an unusually high prevalence of keratoconus. $50 \%$ of corneal transplants performed in New Zealand are due to this debilitating disease, compared with $30 \%$ in Australia ${ }^{2}$ and $20 \%$ in the $\mathrm{UK}^{3}$.

\section{Clinical signs of keratoconus}

The first adequate description of keratoconus, setting it aside from other ectatic conditions, was advanced by Nottingham in 1854 in his treatise 'Practical observations on conical cornea: and on the short sight, and other defects of vision connected with it' ${ }^{\prime}$.

In 1943 Berliner ${ }^{5}$ listed the seven distinct features of keratoconus as classified by Von der Heydt and Appelbaum: 
1. Thinning of the cornea at the apex of the cone

2. Reflex from the endothelial cup

3. Striae

4. Irregular superficial opacities or scars

5. Ruptures in Descemet's membrane

6. Increased visibility of the nerve fibres and

7. Fleischer's ring.

These morphological features became incorporated by Duke-Elder ${ }^{6}$ into the 1965 text 'System of Ophthalmology', which went on to describe keratoconus as a disease which can be recognised by:

1. A thinning of the cornea at the apex of the cone from one half to one fifth of its normal dimensions

2. An endothelial reflex in the central portion of the cornea at the peak of the cone

3. Vertical lines in the deeper layers of the stroma

4. An increased visibility of the nerve fibres which form a network of grey lines interspersed with small dots

5. Fleischer's ring, a line running round the base of the cone

6. Ruptures of Descemet's membrane of characteristic appearance

7. Ruptures in Bowman's membrane in advanced cases producing superficial linear scars.

Rabinowitz ${ }^{1}$ lists the following clinical signs which may be present individually or in combination in moderate to advanced keratoconus:

'Stromal thinning (centrally or paracentrally, most commonly inferiorly or inferotemporally); conical protrusion; an iron line partially or completely surrounding the cone (Fleischer's ring); and fine vertical lines in the deep stroma and Descemet's membrane (Vogt's striae)... Other accompanying signs might include epithelial nebulae, anterior stromal scars, enlarged corneal nerves and increased intensity of the corneal endothelial reflex and subepithelial fibrillary lines.'

Since then advances in corneal topographical assessment have greatly aided the diagnosis of early disease. Prior to topography, forme fruste keratoconus was harder to recognise as patients do not necessarily have symptoms or observable clinical signs in these early stages.

\section{Antero-posterior review of morphological changes in keratoconus}

Pathological and histopathological abnormalities have been documented in every layer of the keratoconic cornea and this has previously been reviewed by our laboratory ${ }^{7}$. The following represents a layer by layer summary of keratoconic morphological variations reported.

\subsection{Epithelium}

Ex vivo histological analysis of keratoconic corneas has demonstrated significant thinning of the central epithelium ${ }^{8}$. Central epithelial thinning was significantly greater in those corneas which also had breaks in the Bowman's layer, however, the authors thought it likely that differences in the integrity of Bowman's layer could nevertheless be considered to be manifestations of the same disease process. Subsequent studies report thickened epithelia in 
keratoconus ${ }^{9,10}$ or else no difference in epithelial thickness between keratoconus and normal controls ${ }^{11}$.

In vivo confocal microscopy studies of the epithelium demonstrate morphological alterations in the area of the keratoconic corneal apex. Elongated superficial epithelial cells, arranged in a whorl-like fashion, can be observed. Near Bowman's membrane highly reflective changes and fold-like structures are visible ${ }^{12}$. These in vivo pathological features may well reflect the oedematous disruptions of basal epithelial integrity in keratoconus.

Apoptotic changes have also been detected in epithelia of keratoconic samples. TUNEL positive epithelial cells were confined to the superficial epithelium of normal corneas while extending further down in keratoconic corneas 9 .This is supported by the work which reported that intense TUNEL labelling was present in the basal epithelia of fifteen out of sixteen keratoconic corneas examined ${ }^{13}$.

The keratoconic basement membrane assumes an irregular appearance and breaks in places ${ }^{14}$. It also undergoes a change in composition 15,16 that cannot be explained by scarring alone. Laminin-1 and laminin-5 staining was shown to be irregular and thickened at defect sites, however monoclonal antibodies against the $\alpha 2$ and $\beta 2$ chains did not react ${ }^{15}$. Type IV collagen $\alpha 1$ and $\alpha 2$ reactivity was also only found in the defect regions of keratoconic or scarred corneas ${ }^{15}$. Immunostaining for type VII collagen was patchily localised to the basement membrane defects ${ }^{15}$. Integrin $\beta 4$ staining which was positive in the basement membrane and the lateral and apical cell membranes of the epithelial cells, was found to be discontinuous in keratoconic corneas ${ }^{15}$. It has been suggested that a process similar to wound healing might account for such differences in structure. Basement membrane alterations may affect critical interactions of the corneal epithelium with the underlying basement membrane, as well as cellmatrix interactions and matrix organization in the stroma ${ }^{16}$.

\subsection{Nerve fibres}

Increased visibility of nerve fibres by slit lamp biomicroscopy has been demonstrated in keratoconus. Corneal nerves pass between the stroma and epithelium at sites of early degradative change ${ }^{17}$. Keratocytes wrap around the nerves as they pass through an otherwise acellular Bowman's layer ${ }^{17}$. Localised nerve thickenings develop in the epithelium and stress epithelial architecture ${ }^{17}$.

\subsection{Bowman's layer}

Scanning electron microscopy has found defects and ruptures in Bowman's layer to varying degrees in all keratoconic corneas examined18. Discontinuities in Bowman's layer are sometimes accompanied by distortion of the stroma beneath the defect ${ }^{15}$ or alternatively, direct contact between epithelial and stromal cells ${ }^{19}$. Rather than being seen throughout the affected cornea, such abnormalities of the extracellular matrix are usually confined to several loci, suggesting a localised focus of disease progression.

\subsection{Stroma - Collagen lamellae and keratocytes}

The thickness of collagen lamellae in keratoconus is unaltered, but the number of lamellae appears to be significantly reduced compared to normal tissue ${ }^{20}$. There is no difference in 
interfibrillar spacing between keratoconus and control corneas, conclusively demonstrating that stromal thinning in keratoconus is not due to closer packing of the fibrils in the stroma.

There is some evidence for a progressive loss of lamellae from the stroma, for example, a reduction in the volume of proteoglycan along the collagen fibrils has been found in keratoconus ${ }^{21}$. Low angle $\mathrm{x}$-ray scattering has shown that the orientation of collagen fibrils within lamellae is also altered in the disease ${ }^{22}$. It is likely that these changes reflect the presence of a degradative process or alternatively, insufficient repair mechanisms. Biochemical analyses of stromal matrix components are inconclusive: Critchfield and coworkers ${ }^{23}$ described decreased collagen and total protein levels in keratoconic tissue by western blotting. Radda et al. ${ }^{24}$ found a 5\% increase in type I collagen in keratoconus; while Zimmermann et al. ${ }^{25}$ found no differences in collagen composition.

Keratoconus is also associated with changes in keratocyte morphology as well as loss of keratocyte density 11,12 . Keratocytes may be lost though apoptosis 9,13 , however, as apoptosis was not seen in all keratoconic samples analysed it was proposed that such cells might not be detected if at the time of analysis the tissue was in a period of keratoconic remission. An alternative explanation suggests that because keratoconus is diagnosed on the basis of clinical findings, there may be several diseases with differing pathophysiological mechanisms that produce the phenotypic change that is referred to as keratoconus.

Keratocyte density was lowest in the anterior-most part of the stroma ${ }^{12}$. Whilst there may be a significant decrease in the density of keratocytes in the stroma immediately underneath Bowmans' membrane, the remaining keratocytes are far from quiet. Such keratocytes and their pseudopodia are oriented apically towards the overlying epithelium and their activated state is reflected by the abundance of rough endoplasmic reticulum within the cells ${ }^{26}$.

Studies of the peripheral keratoconic cornea also show discrete incursions of fine keratocytic processes into Bowman's membrane ${ }^{10}$. These processes were often observed in conjunction with posterior collapse of epithelial cells into the Bowman's layer ${ }^{10}$.

\subsection{Descemet's membrane}

Ruptures and folds in Descemet's membrane are common in keratoconus ${ }^{14}$. The origin of these ruptures is unclear as several studies of extracellular matrix proteins have revealed no differences in the levels of collagens, laminin, entactin or perlecan between keratoconus and normal tissue ${ }^{19,25}$. The appearance of the defects in Descemet's membrane may well be associated with environmental factors such as eye rubbing and may lead to the development of hydrops ${ }^{1}$.

\subsection{Endothelium}

The endothelium may be normal in keratoconus or may demonstrate intracellular dark structures, pleomorphisms or elongation of cells 1 . Scanning slit confocal microscopy and ultrasound biomicroscopy in living patients with keratoconus revealed central detachment of Descemet's membrane and endothelium from the posterior part of the stroma ${ }^{27}$. Ruptures in Descemet's membrane may directly lead to endothelial cell loss by triggering cell membrane perforation, loss of cell contents and edema ${ }^{28}$. Alternatively apoptosis may account for decreased endothelial cell density ${ }^{13}$. 


\subsection{Evidence from recurrence of keratoconus}

The recurrences of keratoconus in patients after penetrating keratoplasty ${ }^{29}$ suggest either a recurrence of the host disease in the graft or else represent transmission of undiagnosed keratoconus from the donor cornea ${ }^{30}$. Histological examination of corneal buttons from patients undergoing repeated penetrating keratoplasty revealed structural changes compatible with a diagnosis of keratoconus in all the examined corneas ${ }^{31}$. Recurrence of keratoconus characteristics may be attributed to graft repopulation by the recipient cells, ageing of the grafted tissue, or both. However a recent study from our own laboratory failed to find evidence of recurrence of keratoconus in patients undergoing regraft surgery 32 .

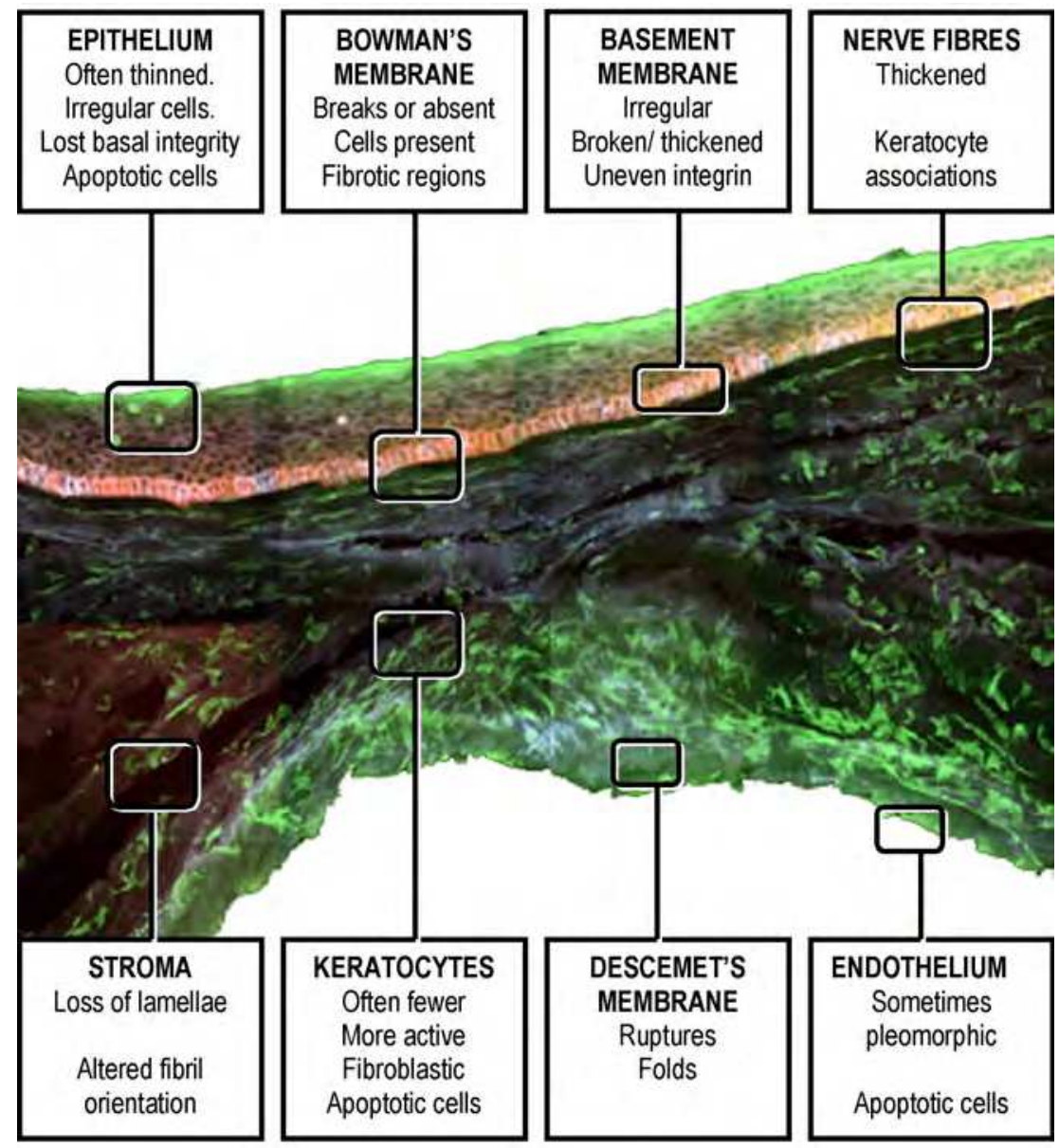

Fig. 1. A diverse range of morphological changes have been described in every layer of the keratoconic cornea. An antero-posterior section of a keratoconic cornea labelled with CellTracker green to highlight cellular morphology and integrin $\alpha 3 \beta 1$ labelling the basal epithelium in red helps to summarise characteristic histopathological abnormalities by corneal layer.

Figure reproduced by permission from Wiley-Blackwells ${ }^{7}$ 


\section{Pathology to pathogenesis}

The diversity of pathologies described for keratoconus are likely to represent temporal differences in the progression of the disease, positional differences relative to the apical centre of maximum damage and reflect a variety of pathophysiological diseases which make up the clinical pigeonhole of keratoconus.

Matrix metalloproteinases (MMPs) have long been suspected of mediating the pathological progression of keratoconus. The cornea is $70 \%$ collagen by weight and the reduced collagen content of the keratoconic cornea suggests a degraded extracellular matrix ${ }^{23}$. Extracellular matrix breakdown is, however, only a small component of the MMP repertoire of activity. Nevertheless, this function is essential for normal remodeling, leading to the constitutive expression of MMPs in healthy tissues.

Various models emphasise the role of MMPs in disease, for example, as mediators of connective tissue destruction in arthritis ${ }^{33}$. Consistent with such an involvement is the MMP hypothesis of keratoconus which proposes that MMPs are over-expressed in the disease while MMP inhibitors may be down-regulated, shifting the balance towards excessive tissue destruction. Over the last decade many studies have set out to measure the levels of MMPs and their inhibitors by a variety of techniques yet over-expression of MMPs or presence of active forms has not been found consistently ${ }^{34}$.

It is important to consider that the relative balance between various MMPs could be more significant than absolute concentrations. This is relevant given that MMPs often undergo intermolecular interactions with each other to achieve activation from the latent form or to target MMP action to a particular site such as the cell surface. Paradoxically, tissue inhibitors of matrix metalloproteinases (TIMPs) can associate with pro form MMPs to trigger proteolytic activity ${ }^{33}$. Tissue degradation in thinning disorders, such as keratoconus, also involves the expression of inflammatory mediators, including proinflammatory cytokines and cell adhesion molecules ${ }^{35}$, which modulate MMP activity and are themselves modulated by it.

The MMP family includes more than 25 members that make up five families based on their substrate preference: collagenases (MMP-1, MMP-8, and MMP-13), stromelysins (MMP-3, MMP-10), matrilysins (MMP-7, MMP-26), gelatinases (MMP-2, MMP-9), membrane type MMPs (MPP-14 to MMP-17, MMP-24) and others ${ }^{36}$. Most are synthesised by resident cells, some are brought in by invading leukocytes. Specific MMPs appear in specific locations within the cornea ${ }^{36}$, likely due to cellular and soluble factors particular to the layer.

MMP changes have been described in every layer of the cornea in keratoconus. The following is a layer by layer summary of MMP changes reported within the last 15 years.

\subsection{Tear film and increased MMP-9}

Tear film composition reflects ocular surface events and tears may therefore be considered a vehicle for some of the pathogenic protagonists of keratoconus. Unfortunately, the cellular origin of any such molecules cannot be determined conclusively as both corneal and noncorneal secretions will be represented in the tear fluid.

In 2000 the presence of collagen degradation products was reported in the tears of patients with keratoconus ${ }^{37}$. The detected telopeptides were presumed to be of corneal origin but the authors conceded that serum and conjunctiva were also potential sources. The conjunctival 
epithelium is indeed altered in keratoconus. Elevation of lysosomal enzyme levels has been found in corneal and conjunctival epithelium ${ }^{38}$ though such enzymes are mostly involved with lipid metabolism, rather than turnover of proteins or connective tissues. Lipids, however, are crucial to the integrity of the tear film and indeed, chronic ocular desiccation and aqueous tear deficiency can produce inferior corneal steepening and high astigmatism resembling keratoconus ${ }^{39}$.

More recently, the levels of interleukin-6 (IL-6), tumour nectosis factor-a (TNF-a), and MMP-9 in the tear fluid of keratoconic patients were measured by enzyme linked immunoadsorbent assay and were found to be significantly higher than in normal subjects ${ }^{40}$. Increases in the levels of these molecules may be intermittent, but sufficient to provoke slowly progressive ectasia ${ }^{40}$. No significant differences in the concentrations of adhesion molecules inter cellular adhesion molecule-1 (ICAM-1) and vascular cell adhesion protein-1 (VCAM-1) were detected and other proteinases were not measured ${ }^{40}$.

In most cases, keratoconus initially affects only one eye and later the ectasia may progress to include both eyes. Lema et al. followed up their initial work by measuring the concentrations of IL-6, TNF- $\alpha$ and MMP-9 in thirty patients with unilateral keratoconus one eye diagnosed with keratoconus and the other eye having subclinical disease. IL- 6 and TNF-a levels were found to be raised in both eyes in patients with asymmetric keratoconus, however, only TNF- $\alpha$ was significantly higher in the keratoconic eye, with respect to the subclinical one. Increased MMP-9 levels were found in keratoconic eyes only ${ }^{35}$.

TNF-a has been shown to upregulate MMP-9 expression in human corneal epithelial cells ${ }^{41}$ and such proinflammatory cytokines are present at the ocular surface even in the absence of inflammation ${ }^{42}$. Interestingly, increased concentrations of cytokines are found in tears from various ocular allergic disease states ${ }^{43}$. While atopy is associated with keratoconus ${ }^{44}$, multivariate analysis has shown that the contribution to pathogenesis likely occurs from the eye rubbing encouraged by the itch of atopy rather than from chemical mediators associated with atopy itself 45 .

The keratoconic ocular surface is characterised by a disorder of tear quality, decreased corneal sensitivity, conjunctival squamous metaplasia and higher fluorescein and rose bengal staining scores, all of which seem to relate to the extent of keratoconus progression ${ }^{46}$. In that respect the ocular surface is not unlike that of dry eye. It has been shown that inflammation plays an important role in both of these conditions and MMP-9 is found in the tears of both ${ }^{40,47}$.

In fact MMP-9 accumulation has been demonstrated in several other disorders with an inflammatory basis, for example, in tears of patients with peripheral ulcerative keratitis, herpetic keratitis and Sjogren's syndrome ${ }^{48}$.

Among the MMPs, MMP-9 is of central importance in cleaving epithelial basement membrane components and tight junction proteins that maintain corneal epithelial barrier function ${ }^{47}$. MMP-9 belongs to the gelatinase group of metalloproteinases that degrade denatured collagen; native collagens type IV, V, and VII; and elastin ${ }^{47}$. Expression of MMP-9 by ocular surface epithelia in normal healthy eyes is low. Indeed, MMP-9 knockout mice show significantly less alteration of epithelial barrier function in response to experimental desiccating stress than do wild-type mice, an effect abrogated by topical application of MMP-9 to the ocular surface ${ }^{49}$. 


\subsection{Whole cornea studies and decreased TIMP-1}

Studies have also assessed levels of various degradative enzymes in whole processed keratoconic corneas. This research was triggered by observations that cultured human dermal fibroblasts exposed to reactive oxygen species go on to upregulate MMP-1 and MMP-2 mRNA while downregulating TIMP-2 mRNA50,51. Thus oxidative stress was thought to be a contributing factor to the pathogenesis of keratoconus by promoting, amongst others, degradative activity.

Kenney et al. measured RNA levels by semi-quantitative reverse transcription-polymerase chain reaction (RT-PCR) and Southern blot. MMP-1, -2, -7, -9, -14, TIMP-2 and TIMP-3 mRNA levels did not differ between normal and keratoconic corneas ${ }^{52}$. There was, however, a 1.8 fold decrease in TIMP-1 mRNA and 2.8 fold decrease in TIMP-1 protein in keratoconus ${ }^{52}$.

Decreased TIMP-1 may account for the high gelatinase activity and increased apoptosis of keratoconus. It has been proposed that TIMP-1 curtails the activity of MMP-2, the major protease of the corneal stroma. Unlike the constitutively expressed TIMP-2, TIMP-1 is an inducible inhibitor generally confined to the corneal epithelium ${ }^{53}$. Its synthesis seems to be upregulated in stromal cell cultures from scarred keratoconic corneas ${ }^{53}$. Apart from its antiproteinase role TIMP-1 prevents TIMP-3 mediated stromal cell apoptosis 53 . Dysequilibrium in the TIMP-1/TIMP-3 system can thus, at least partially, account for the keratoconic condition.

It is likely that changes in MMP and TIMP systems are also present in several other eye diseases. For example, diabetic retinopathy corneas contain higher levels of MMP-3 and MMP-10 mRNA as measured by RT-PCR compared with keratoconic corneas ${ }^{54}$. This is thought to account for the various basement membrane and extracellular matrix alterations in the cornea of diabetic retinopathy.

\subsection{Epithelium and increased MMP-1}

Collier et al. performed peroxidase immunohistochemistry and determined that MMP-14 (MT1-MMP) was significantly elevated in the epithelium of keratoconic corneas compared to eye bank controls, while MMP-2 was not ${ }^{55}$. This was surprising given that MMP-14 was previously shown to activate latent MMP-2 as well as being able to degrade matrix molecules directly. MMP-14 forms a tri-molecular complex on the cell surface with MMP-2 and TIMP-2 in a complex sequence ${ }^{55}$. The timing of this interaction and concentrations of component molecules determine whether the MMP-14 active site is exposed and available for MMP-2 activation and matrix degradation ${ }^{55}$.

It was also noted that the expression of MMP-14 in control corneas varied considerably from virtually none to pronounced levels, raising the possibility that the enzyme is expressed in response to any minor inflammatory or other pathological event.

Subsequent work failed to detect a significant difference in either MMP-2 or MMP-14 between keratoconic and normal epithelium ${ }^{56}$, instead reporting higher levels of MMP-13 in the keratoconic epithelium compared to healthy specimens ${ }^{56}$. TNF- $\alpha$ and IL-1 $\beta$ increase corneal epithelial MMP-13 synthesis ${ }^{57}$ while MMP-13 has been shown to activate MMP-9 in vitro ${ }^{58}$. The temporal and spatial correlation between MMP-13, MMP-9 and corneal re-epithelialisation suggests that MMP-13 plays a role in corneal reepithelialisation after injury ${ }^{59}$. MMP-13 activation seems to be much more prominent in bullous keratopathy than keratoconus ${ }^{60}$. 
Several studies report increased MMP-1 expression in keratoconus. The epithelia of healthy corneas and corneas with post LASIK keratectasia display nearly absent immunolabelling for MMP-1, whereas strong labelling occurs in the epithelium and stroma of keratoconic specimens $56,61,62$. MMP-1 is able to degrade many non-collagenous components of the extracellular matrix, including fibronectin, laminin, and basement membrane glycoproteins, but first and foremost, it cleaves native interstitial collagens types I and III62.

MMP-1 can be effectively induced by the extracellular matrix metalloproteinase inducer (EMMPRIN), which is a member of the immunoglobulin superfamily of adhesion molecules ${ }^{62}$. In keratoconus, EMMPRIN expression was found in all layers of the cornea, especially in histopathologically altered areas, however, the distribution of MMP-1 did not totally overlap with histologically apparent corneal damage and EMMPRIN expression ${ }^{62}$. This may be because EMMPRIN upregulates other MMPs (MMP-2, MMP-3) in stromal fibroblasts. In areas of destruction EMMPRIN-inducible MMPs, other than MMP-1, may be participating in the local pathological process.

MMP-8 seems to be down-regulated in keratoconic epithelium compared to normal controls ${ }^{56}$. MMP-8 plays a paradoxical role in tissues, on the one hand being able to cleave collagens despite the presence of TIMPs and on the other controlling the inflammatory load in tissues by downregulating the polymorphonuclear (PMN) burden63. Unlike other MMPs epithelial MMP-8 is not upregulated by TNF- $\alpha$ and IL-1 $\beta^{57}$. Such MMPs may contribute to the pathogenesis of keratoconus by proteolytic modulation of proinflammatory cytokines or chemokines or the generation of apoptotic signals for inflammatory and corneal cells.

\subsection{Stroma}

Despite much research, contradictory reports preclude any conclusive statement on the contribution of specific MMPs to histopathological hallmarks found in the keratoconic corneal stroma.

In one study MMP-1, -2 and -13 immunolabelling was noted to be greater in keratoconic samples compared to normal controls while no difference in MMP-8 or MMP-14 immunolabelling was observed ${ }^{56}$. In another study, keratoconic immunolabelling for MMP$1,-2$ and -3 resembled that of the normal cornea and post LASIK keratectasia ${ }^{6}$ while peroxidase immunohistochemistry performed by Collier's group showed that MMP-14 was significantly elevated in the keratoconic stroma ${ }^{55}$.

Stromal tissue layer supernatant showed no significant difference in MMP-2, MMP-9, pro MMP-13 and TIMP-1 concentrations between bullous keratopathy and keratoconus ${ }^{60}$. Keratocyte cultures from normal and keratoconic corneas also showed no significant changes in mRNA levels for MMP-1, -2, -3, TIMP-1, or TIMP-264. Only TIMP-1 protein was decreased, prompting a three-fold increase in the MMP-2/TIMP-1 ratio in keratoconus ${ }^{64}$.

Yet stromal cell cultures performed by Smith et al. found MMP-2 to be over-expressed in clear keratoconic and scarred keratoconic corneas ${ }^{65}$. The quantities of TIMP-1 and TIMP-2 in normal and clear keratoconic cultures were similar. Scarred keratoconic cultures overexpressed TIMP-165. In these cultures the cells remained healthy and the extent of stress induced MMP-2 activation was low ${ }^{65}$. For this reason, in addition to inhibiting MMP activity, upregulated TIMP-1 production may be a feature of corneal scar tissue cells that are refractory to dying. Alternatively, TIMP-1 may prevent cell death that is conceivably initiated by upregulated TIMP-3 production and sequestration in the extracellular matrix ${ }^{65}$. 


\subsection{Endothelium with Descemet's}

There are only a few studies assessing MMP changes specific to Descemet's membrane and endothelium. The endothelial monolayer often gets damaged or lost as the result of tissue handling making studies technically difficult. It was noted that endothelial cells and Descemet's membrane were pathologically altered in keratoconus and EMMPRIN was expressed next to areas of histological damage without, however, any evidence of MMP-1 expression in the area62. Mackiewicz et al. did not detect a difference in MMP-1, -13 and -14 between keratoconus and healthy controls but did report more MMP-2 in the endothelium and Descemet's of keratoconus and less MMP-8 in the same layers compared to normal controls ${ }^{56}$. Endothelial tissue supernatant showed no significant difference in MMP-2, MMP9, pro MMP-13 and TIMP-1 concentrations between bullous keratopathy and keratoconus ${ }^{60}$.

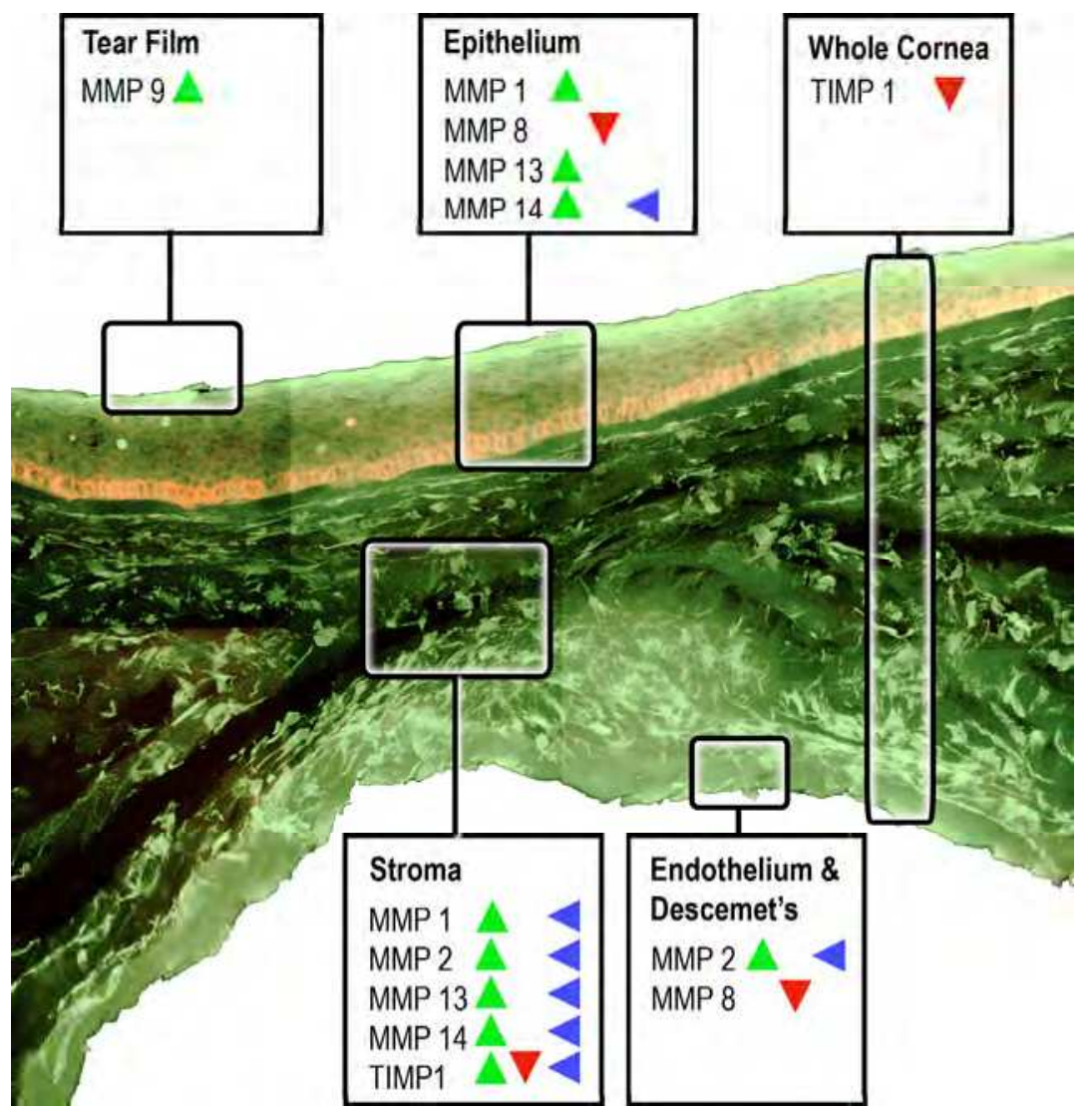

Fig. 2. Matrix metalloproteinase (MMP) and tissue inhibitor of matrix metalloproteinase (TIMP) changes have been described in every layer of the keratoconic cornea. Again, an antero-posterior section of a keratoconic cornea illustrated the MMP and TIMP molecules whose expression have been reported as altered in keratoconus. Green arrows represent increased expression, whilst red represents reported decreased expression and blue no change. It is evident in several cases that reported expression profiles are cotradictory. 


\section{Conclusion}

MMPs are a group of proteolytic enzymes that are able to degrade the main components of the extracellular matrix and corneal membranes. Owing to these activities, MMPs are widely assumed to have a central role in the pathogenesis of keratoconus. However, studies have shown that MMPs can also handle substrates distinct from extracellular matrix proteins, influencing cell processes such as apoptosis. Proteolytic modulation of proinflammatory cytokines or chemokines or the generation of apoptotic signals for resident and inflammatory cells may prove to be as important in mediating keratoconus progression as purported extracellular matrix degradation.

The involvement of proteases in keratoconus has been the subject of much research; however, the exact nature of proteolytic phenomena that contribute to keratoconus progression remains unclear. Studies have described upregulation of MMP-1, MMP-2, MMP-9, MMP-13 and MMP-14 in keratoconus, yet this has not been seen consistently. Other authors report no change in MMP levels or else a downregulation of MMP-8 or TIMP-1. Increased activity of other proteinases such as cathepsins ${ }^{66}$ likely contributes to the structural deterioration seen in keratoconus.

For MMP inhibition or TIMP upregulation to be considered a valid therapeutic target for amelioration of the disease process it is important to know exactly which MMPs are culpable. However, due to complex inter-molecular interactions between individual members of the MMP family, the ratios between various MMPs may turn out to be more significant to keratoconus pathogenesis than absolute concentrations of specific MMPs. The ability to measure multiple MMPs in a single corneal specimen is therefore necessary in order to understand the interplay of proteinases within the cornea. Tear fluid analysis affords the opportunity to investigate keratoconus protagonists in the earlier stages of the disease, a significant advantage over end-stage corneal tissue analysis. MMP changes are seen in many other corneal diseases, suggesting that MMP activation may be a nonspecific response to corneal insult. Indeed, the observed changes in inflammatory mediators or MMP levels within the cornea can in fact be epiphenomena of changes in corneal structure ${ }^{35}$. It is also possible that several diseases, with differing pathophysiology produce the phenotypic changes that are called keratoconus, accounting for the difference in proteinase profiles of examined keratoconic samples.

\section{References}

[1] Rabinowitz YS. Keratoconus. Surv Opthalmol. 1998; 42:297-319.

[2] Williams KA, Muehlberg SM, Lewis RF, Coster DJ. How succesful is corneal transplantation? A report from the Australian corneal graft register. Eye (Lond). 1995; 9:219-227.

[3] Vail A, Gore SM, Bradley BA, Easty DL, Rogers CA. Corneal transplantation in the United Kingdom and Northern Ireland. Brit J Ophthalmol. 1993; 77:650-6.

[4] Nottingham J. Practical observations on conical cornea: and on the short sight, and other defects of vision connected with it. 1854; London, John Churchill.

[5] Berliner ML. Biomicroscopy of the eye. 1943; New York, Paul B Hoeber Inc.

[6] Duke-Elder S. System of Ophthalmology. Vol VIII Diseases of the outer eye. 1965; London, Henry Kimpton.

[7] Sherwin T, Brookes NH. Morphological changes in keratoconus: pathology or pathogenesis. Clin Experiment Ophthalmol. 2004; 32(2):211-7. 
[8] Scroggs MW, Proia AD. Histopathological variation in keratoconic corneas. Cornea. 1992; 11:553-559.

[9] Kim W-J, Rabinowitz YS, Meisler DM, Wilson SE. Keratocyte apoptosis associated with keratoconus. Exp Eye Res. 1999; 69:475-481.

[10] Sherwin T, Brookes NH, Loh I-P, Poole CA, Clover GM. Cellular incursion into Bowman's membrane in the peripheral cone of the keratoconic cornea. Exp Eye Res. 2002; 74:473-482.

[11] Erie JC, Patel SV, McLaren JW, Nau CB, Hodge DO, Bourne WM. Keratocyte density in keratoconus: A confocal microscopy study. Am J Ophth. 2002; 134:689-695.

[12] Somodi S, Hahnel C, Slowik C, Richter A, Weiss DG, Guthoff R. Confocal in vivo microscopy and confocal laser scanning fluorescence microscopy in keratoconus. Ger J Ophthalmol. 1997; 5:518-525.

[13] Kaldawy RM, Wagner J, Ching S, Seigel GM. Evidence of apoptotic cell death in keratoconus. Cornea. 2002; 21:206-209.

[14] Teng CC. Electron microscope study of the pathology of keratoconus: Part I. Am J Ophthalmol. 1963; 55:19-47.

[15] Tuori AJ, Virtanen I, Aine E, Kalluri R, Miner JH, Uusitalo HM. The immunohistochemical composition of corneal basement membrane in keratoconus. Curr Eye Res. 1997; 16:792-801.

[16] Cheng EL, Maruyama I, SundarRaj N, Sugar J, Feder RS, Yue BY. Expression of type XII collagen and hemidesmosome-associated proteins in keratoconus corneas. Curr Eye Res. 2001; 22:333-340.

[17] Brookes NH, Loh I-P, Clover GM, Poole CA, Sherwin T. Involvement of corneal nerves in the progression of keratoconus. Exp Eye Res. 2003; 77:515-524.

[18] Sawaguchi S, Fukuchi T, Abe H, Kaiya T, Sugar J, Yue, BT. Three dimensional scanning electron microscopic study of keratoconus corneas. Arch Ophthalmol. 1998; 116:62-68.

[19] Kenney MC, Nesburn AB, Burgeson RE, Butkowski RJ, Ljubimov AV. Abnormalities of the extracellular matrix in keratoconus corneas. Cornea. 1997; 16:345-51.

[20] Takahashi A, Nakayasu K, Okisaka S, Kanai A. Quantitative analysis of collagen fibres in keratoconus. Acta Soc Ophthalmol Jap. 1990; 90:1068-73.

[21] Fullwood NJ, Tuft SJ, Malik NS, Meek KM, Ridgway AEA, Harrison RJ. Synchrotron Xray diffraction studies of keratoconus corneal stroma. Invest Ophthalmol Vis Sci. 1992; 33:1734-41.

[22] Daxer A, Fratzl P. Collagen fibril orientation in the human corneal stroma and its implication in keratoconus. Invest Ophthalmol Vis Sci. 1997; 38:1289-90.

[23] Critchfield JW, Calandra AJ, Nesburn AB, Kenney MCR. Keratoconus I. Biochemical Studies. Exp Eye Res. 1988; 46:953-64.

[24] Radda TM, Menzel EJ, Freyler H, Gnad HD. Collagen types in keratoconus. Graefes Arch Clin Exp Ophthalmol. 1982; 218:262-6.

[25] Zimmermann DR, Fischer RW, Winterhalter KH, Witmer R, Vaughan L. Comparative studies of collagens in normal and keratoconus corneas. Exp Eye Res. 1988; 46:431-42.

[26] Rock ME, Moore MN, Anderson JA, Binder PS. 3-D computer models of human keratocytes. CLAO J. 1995; 21:57-60.

[27] Wygledowska-Promienska D, Rokita-Wala I, Gierek-Ciaciura S, Piatek-Koronowska G. The alterations in corneal structure at III/IV stage of keratoconus by means of confocal microscopy and ultrasound biomicroscopy before penetrating keratoplasty. Klinika Oczna. 1999; 101:427-432.

[28] Jongebloed WL, Dijk F, Worst JG. Keratoconus morphology and cell dystrophy: a SEM study. Documenta Ophthalmologica. 1989; 72:403-409. 
[29] Bechrakis N, Blom ML, Stark WJ, Green WR. Recurrent keratoconus. Cornea. 1994; 13:73-77.

[30] Krivoy D, McCormick S, Zaidman GW. Postkeratoplasty keratoconus in a nonkeratoconus patient. Am J Ophthalmol. 2001; 131:653-654.

[31] Bourges J-L, Salvoldelli M, Dighiero P, Assouline M, Pouliquen Y, BenEzra D, Renard G, Behar-Cohen F. A clinical and histologic follow up analysis of donor grafts. Ophthalmol. 2003; 110:1920-1925.

[32] Brookes NH, Niederer RL, Hickey DG, McGhee CNJ, Sherwin T. Recurrence of keratoconic pathology in penetrating keratoplasty buttons originally transplanted for keratoconus. Cornea. 2009; 28: 688-693.

[33] Brinckerhoff CE, Matrisian LM. Matrix metalloproteinases: a tail of a frog that became a prince. Nat Rev Mol Cell Biol. 2002; 3(3):207-14.

[34] Collier SA. Is the corneal degradation in keratoconus caused by matrixmetalloproteinases? Clin Experiment Ophthalmol. 2001; 29(6):340-4.

[35] Lema I, Sobrino T, Durán JA, Brea D, Díez-Feijoo E. Subclinical keratoconus and inflammatory molecules from tears. Br J Ophthalmol. 2009; 93(6):820-4.

[36] Fournié PR, Gordon GM, Dawson DG, Edelhauser HF, Fini ME. Correlations of longterm matrix metalloproteinase localization in human corneas after successful laserassisted in situ keratomileusis with minor complications at the flap margin. Arch Ophthalmol. 2008; 126(2):162-70.

[37] Abalain JH, Dossou H, Colin J, Floch HH. Levels of collagen degradation products (telopeptides) in the tear film of patients with keratoconus. Cornea. 2000; 19:474-6.

[38] Fukuchi T, Yue BY, Sugar J, Lam S. Lysosomal enzyme activities in conjunctival tissues of patients with keratoconus. Arch Ophthalmol. 1994; 112(10):1368-74.

[39] De Paiva CS, Harris LD, Pflugfelder SC. Keratoconus-like topographic changes in keratoconjunctivitis sicca. Cornea. 2003; 22(1):22-4.

[40] Lema I, Durán JA. Inflammatory molecules in the tears of patients with keratoconus. Ophthalmology. 2005; 112(4):654-9.

[41] Li DQ, Lokeshwar BL, Solomon A, Monroy D, Ji Z, Pflugfelder SC. Regulation of MMP9 production by human corneal epithelial cells. Exp Eye Res. 2001; 73:449-59.

[42] Sonoda S, Uchino E, Nakao K, Sakamoto T. Inflammatory cytokine of basal and reflex tears analysed by multicytokine assay. Br J Ophthalmol. 2006; 90(1):120-2.

[43] Cook EB. Tear cytokines in acute and chronic ocular allergic inflammation. Curr Opin Allergy Clin Immunol. 2004; 4(5):441-5.

[44] Jacq PL, Sale Y, Cochener B, Lozach P, Colin J. Keratoconus, changes in corneal topography and allergy. Study of 3 groups of patients. J Fr Ophtalmol. 1997; 20(2):97-102.

[45] Bawazeer AM, Hodge WG, Lorimer B. Atopy and keratoconus: a multivariate analysis. Br J Ophthalmol. 2000; 84(8):834-6.

[46] Dogru M, Karakaya H, Özçetin H, Ertürk H, Yücel A, Ozmen A, Baykara M, Tsubota K. Tear function and ocular surface changes in keratoconus. Ophthalmology. 2003; 110:1110-8.

[47] Chotikavanich S, de Paiva CS, Li de Q, Chen JJ, Bian F, Farley WJ, Pflugfelder SC. Production and activity of matrix metalloproteinase- 9 on the ocular surface increase in dysfunctional tear syndrome. Invest Ophthalmol Vis Sci. 2009; 50(7):3203-9.

[48] Smith VA, Rishmawi H, Hussein H, Easty DL. Tear film MMP accumulation and corneal disease. Br J Ophthalmol 2001; 85:147-53.

[49] Pflugfelder SC, Farley W, Luo L, Chen LZ, de Paiva CS, Olmos LC, Li DQ, Fini ME. Matrix metalloproteinase- 9 knockout confers resistance to corneal epithelial barrier disruption in experimental dry eye. Am J Pathol. 2005; 166(1):61-71.

[50] Brenneisen P, Briviba K, Wlaschek M, Wenk J, Scharffetter-Kochanek K. Hydrogen peroxide (H2O2) increases the steady-state mRNA levels of collagenase/MMP-1 in human dermal fibroblasts. Free Radic Biol Med. 1997; 22(3):515-24. 
[51] Kawaguchi Y, Tanaka H, Okada T, Konishi H, Takahashi M, Ito M, Asai J. The effects of ultraviolet $\mathrm{A}$ and reactive oxygen species on the mRNA expression of 72-kDa type IV collagenase and its tissue inhibitor in cultured human dermal fibroblasts. Arch Dermatol Res. 1996; 288(1):39-44.

[52] Kenney MC, Chwa M, Atilano SR, Tran A, Carballo M, Saghizadeh M, Vasiliou V, Adachi W, Brown DJ. Increased levels of catalase and cathepsin V/L2 but decreased TIMP-1 in keratoconus corneas: evidence that oxidative stress plays a role in this disorder. Invest Ophthalmol Vis Sci. 2005; 46(3):823-32.

[53] Matthews FJ, Cook SD, Majid MA, Dick AD, Smith VA. Changes in the balance of the tissue inhibitor of matrix metalloproteinases (TIMPs)-1 and -3 may promote keratocyte apoptosis in keratoconus. Exp Eye Res. 2007 Jun; 84(6):1125-34.

[54] Saghizadeh M, Brown DJ, Castellon R, Chwa M, Huang GH, Ljubimova JY, Rosenberg S, Spirin KS, Stolitenko RB, Adachi W, Kinoshita S, Murphy G, Windsor LJ, Kenney $\mathrm{MC}$, Ljubimov AV. Overexpression of matrix metalloproteinase-10 and matrix metalloproteinase-3 in human diabetic corneas: a possible mechanism of basement membrane and integrin alterations. Am J Pathol. 2001; 158(2):723-34.

[55] Collier SA, Madigan MC, Penfold PL. Expression of membrane-type 1 matrix metalloproteinase (MT1-MMP) and MMP-2 in normal and keratoconus corneas. Curr Eye Res. 2000; 21(2):662-8.

[56] Mackiewicz Z, Määttä M, Stenman M, Konttinen L, Tervo T, Konttinen YT. Collagenolytic proteinases in keratoconus. Cornea. 2006; 25(5):603-10.

[57] Li DQ, Shang TY, Kim HS, Solomon A, Lokeshwar BL, Pflugfelder SC. Regulated expression of collagenases MMP-1, -8, and -13 and stromelysins MMP-3, -10, and 11 by human corneal epithelial cells. Invest Ophthalmol Vis Sci. 2003; 44(7):2928-36.

[58] Knäuper V, Smith B, López-Otin C, Murphy G. Activation of progelatinase B (proMMP9) by active collagenase-3 (MMP-13). Eur J Biochem. 1997; 248(2):369-73.

[59] Ye HQ, Maeda M, Yu FS, Azar DT. Differential expression of MT1-MMP (MMP-14) and collagenase III (MMP-13) genes in normal and wounded rat corneas. Invest Ophthalmol Vis Sci. 2000; 41(10):2894-9.

[60] Predović J, Balog T, Marotti T, Gabrić N, Bohac M, Romac I, Dekaris I. The expression of human corneal MMP-2, MMP-9, proMMP-13 and TIMP-1 in bullous keratopathy and keratoconus. Coll Antropol. 2008; 32 Suppl 2:15-9.

[61] Meghpara B, Nakamura H, Macsai M, Sugar J, Hidayat A, Yue BY, Edward DP. Keratectasia after laser in situ keratomileusis: a histopathologic and immunohistochemical study. Arch Ophthalmol. 2008; 126(12):1655-63.

[62] Seppälä HP, Määttä M, Rautia M, Mackiewicz Z, Tuisku I, Tervo T, Konttinen YT. EMMPRIN and MMP-1 in keratoconus. Cornea. 2006; 25(3):325-30.

[63] Owen CA, Hu Z, Lopez-Otin C, Shapiro SD. Membrane-bound matrix metalloproteinase-8 on activated polymorphonuclear cells is a potent, tissue inhibitor of metalloproteinaseresistant collagenase and serpinase. J Immunol. 2004; 172(12):7791-803.

[64] Kenney MC, Chwa M, Opbroek AJ, Brown DJ. Increased gelatinolytic activity in keratoconus keratocyte cultures. A correlation to an altered matrix metalloproteinase2/ tissue inhibitor of metalloproteinase ratio. Cornea. 1994; 13(2):114-24. '

[65] Smith VA, Matthews FJ, Majid MA, Cook SD. Keratoconus: matrix metalloproteinase-2 activation and TIMP modulation. Biochim Biophys Acta. 2006; 1762(4):431-9.

[66] Zhou L, Sawaguchi S, Twining SS, Sugar J, Feder RS, Yue BY. Expression of degradative enzymes and protease inhibitors in corneas with keratoconus. Invest Ophthalmol Vis Sci. 1998; 39(7):1117-24. 


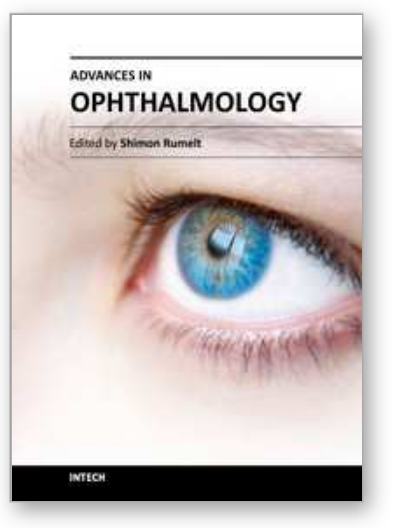

\author{
Advances in Ophthalmology \\ Edited by Dr Shimon Rumelt
}

ISBN 978-953-51-0248-9

Hard cover, 568 pages

Publisher InTech

Published online 07, March, 2012

Published in print edition March, 2012

This book focuses on the different aspects of ophthalmology - the medical science of diagnosis and treatment of eye disorders. Ophthalmology is divided into various clinical subspecialties, such as cornea, cataract, glaucoma, uveitis, retina, neuro-ophthalmology, pediatric ophthalmology, oncology, pathology, and oculoplastics. This book incorporates new developments as well as future perspectives in ophthalmology and is a balanced product between covering a wide range of diseases and expedited publication. It is intended to be the appetizer for other books to follow. Ophthalmologists, researchers, specialists, trainees, and general practitioners with an interest in ophthalmology will find this book interesting and useful.

\title{
How to reference
}

In order to correctly reference this scholarly work, feel free to copy and paste the following:

Dasha Nelidova and Trevor Sherwin (2012). Keratoconus Layer by Layer - Pathology and Matrix Metalloproteinases, Advances in Ophthalmology, Dr Shimon Rumelt (Ed.), ISBN: 978-953-51-0248-9, InTech, Available from: http://www.intechopen.com/books/advances-in-ophthalmology/the-matrix-metalloproteinasehypothesis-of-keratoconus-layer-by-layer

\section{INTECH}

open science | open minds

\section{InTech Europe}

University Campus STeP Ri Slavka Krautzeka 83/A 51000 Rijeka, Croatia

Phone: +385 (51) 770447

Fax: +385 (51) 686166 www.intechopen.com

\section{InTech China}

Unit 405, Office Block, Hotel Equatorial Shanghai No.65, Yan An Road (West), Shanghai, 200040, China 中国上海市延安西路65号上海国际贵都大饭店办公楼 405 单元 Phone: +86-21-62489820

Fax: +86-21-62489821 
(C) 2012 The Author(s). Licensee IntechOpen. This is an open access article distributed under the terms of the Creative Commons Attribution 3.0 License, which permits unrestricted use, distribution, and reproduction in any medium, provided the original work is properly cited. 